\title{
Hyaluronic Acid in the Treatment of Knee Osteoarthritis: Review
}

\author{
Satish Prasad Koiri1,2, Yi Yang'2, Huang Kui2* \\ ${ }^{1}$ School of Medicine, Yangtze University, Jingzhou, China \\ ${ }^{2}$ Department of Orthopaedic, First Affiliated Hospital of Yangtze University, Jingzhou, China \\ Email: ${ }^{\star 2232813795 @ q q . c o m ~}$
}

How to cite this paper: Koiri, S.P., Yang, Y. and Kui, H. (2018) Hyaluronic Acid in the Treatment of Knee Osteoarthritis: Review. Yangtze Medicine, 2, 62-72. https://doi.org/10.4236/ym.2018.22007

Received: March 12, 2018

Accepted: June 8, 2018

Published: June 11, 2018

Copyright $\odot 2018$ by authors and Scientific Research Publishing Inc. This work is licensed under the Creative Commons Attribution International License (CC BY 4.0).

http://creativecommons.org/licenses/by/4.0/

\begin{abstract}
Knee osteoarthritis (OA) is a progressive disease in which the cartilage (cushioning between joints) wears away. As the cartilage wears away, it becomes frayed and rough, and the protective space between the bones decreases. This causes rubbing of bones, resulting in pain, swelling, stiffness, decreased ability to move and formation of bone spurs. Osteoarthritis develops slowly and the pain it causes worsens over time. Although there is no cure, there are many treatment options available to help manage pain and keep people staying active. Intra-articular (IA) hyaluronic acid (HA) injection is one of the treatment options. Hyaluronic acid is a polysaccharide, an anionic, non-sulfated glycosaminoglycan and is a naturally occurring substance found in the synovial fluid surrounding joints. It acts as a lubricant to enable bones to move smoothly over each other and as a shock absorber for joint loads. People with knee osteoarthritis have lower concentration and altered volume of hyaluronic acid than normal in their joints. Due to lower concentration and volume, exogenous hyaluronic acid may be injected into the knee joint. Treatment with exogenous hyaluronic acid contributes to restore the elastic and viscous properties of the synovial fluid, pain reduction and functional improvement. It is indicated for patients who have failed to respond adequately to conservative non-pharmacological therapy and simple analgesic.
\end{abstract}

\section{Keywords}

Osteoarthritis, Intra-Articular, Hyaluronic Acid, Viscosupplementation

\section{Introduction}

$\mathrm{OA}$ is the most common disease of movable joints affecting mainly the knee, hip and hands. It is estimated that $10 \%-20 \%$ of the population worldwide are af-

*Corresponding author. 
fected-among them $10 \%$ of men and $18 \%$ of women are above 60 years of age [1]. This multifactorial and heterogeneous disease is mainly characterized by articular cartilage degradation, inflammation of the synovial membrane and sclerosis of subchondral bone associated with the formation of osteophytes [2]. Although there is no cure, there are many treatment options available to help control pain and improve function and patient's quality of life. The treatment includes non-pharmacological interventions such as acupuncture, balneotherapy/Spa therapy, biomechanical interventions, cane (walking stick), crutches, electrotherapy/neuromuscular electrical stimulation, exercise (land-based and water-based), strength training, self-management and education, TENS (Transcutaneous electric nerve stimulation), ultrasound and weight management [2]. The pharmacological treatment options include acetaminophen (paracetamol), avocado soybean unsaponifiables (ASU), capsaicin, corticosteroids (Intra-articular Injection), chondroitin, diacerein, duloxetine, glucosamine, hyaluronic acid (Intra-articular Injection), non-steroidal anti-inflammatory drugs (Oral Non-selective NSAIDs, Oral COX-2 Inhibitors, topical), opioids (transdermal, oral), risedronate and rosehip [2]. The surgical intervention should be considered only after pharmacological and non-pharmacological treatments have failed [3].

The most appropriate treatment choice depends on the clinical history, contraindications and how well the patient would be able to tolerate the treatment being considered. Especially in cases where the target patient group is of advanced age and simple treatment methods have not been successful, injections are being preferred more because of the potential side effects of NSAIDs [4] [5] [6] [7]. Intra-articular hyaluronan has become a widely accepted option in clinical practice by physicians for the treatment of knee pain due to OA.

HA is a key molecule in the joint biomechanics. In OA and other arthropathies, the reduction in concentration and molecular weight of endogenous HA greatly alters the properties of the synovial fluid, causing cartilage damage and worsening OA symptoms [8]. Thus, exogenous HA is injected into the osteoarthritic knee. The exact mechanism of action of injected HA is not well understood. HA agents are generally administered as a weekly injection over a course of 3 - 5 weeks, and although they have a slower onset of action relative to steroid treatment, the pain relief obtained generally lasts longer-for up to several months [9] [10] [11]. Besides weekly injection over a course of 3 - 5 weeks, the single injection regimen is also in practice. The purpose of this review was to study the safety and recommendation of intra-articular hyaluronic acid injections in the treatment of knee OA.

\section{Mediators Related to $\mathrm{OA}$}

Catabolic and anabolic mediators that have been found to play key roles in articular cartilage homeostasis and the development of OA are shown in Table 1. Disruption of matrix equilibrium and subsequent cartilage degradation is seen 
Table 1. Notable mediators in OA [16].

\begin{tabular}{ccc}
\hline Inflammatory mediators & Signaling mediators & Proteases \\
\hline TNF & NF $\kappa$ B & MMP-1 \\
IL-1 $\beta$ & ERK1/2 & MMP-3 \\
IL-6 & p38 & MMP-9 \\
IL-8 & JNK & MMP-13 \\
IL-15 & PKC $\delta$ & ADAMTS-4 \\
IL-17 & TLRs & ADAMTS-5 \\
IL-21 & $\beta$-cantenin & TACE \\
PGE2 & Gli1 & \\
Substance P & Ptch & \\
NGF & HHIP & \\
EGF & HIF-2 $\alpha$ & \\
VEGF & Inos & \\
FGF-2 & RUNX2 & \\
\hline
\end{tabular}

by the up-regulation of catabolic processes and/or down-regulation of anabolic processes [12] [13] [14] [15].

\section{Indications}

1) Should be considered in patients with significantly symptomatic $O A$ who have not responded adequately to non-pharmacological and pharmacological treatments or are intolerant of these therapies (e.g., gastrointestinal problems related to anti-inflammatory medications) [17].

2) Patients who are not candidate for total knee replacement or who have failed previous knee surgery for their arthritis, such as arthroscopic debridement.

3) Total knee replacement in younger patients may be delayed by the use of hyaluronic acid [18] [19].

\section{Technique for Intra-Articular Knee Injection}

A knee joint can be injected in several ways.

1) Patient in sitting position with legs off the side of the table or chair [20] [21].

2) Patient in supine position with the knee flexed 90 degree or 20 - 30 degree [21] [22] [23] [24].

3) Patient in supine position with the knee extended [21] [22] [24] [25].

For patients in sitting position, legs are off the side of the table or chair. Mark the injection site and clean the skin thoroughly with a povidone iodine preparation (Betadine) and alcohol. For finding the injection site, palpate the patellar tendon and then fall off either medial or lateral side. The depression (dimple) just to the inferior pole of the patella is the injection site. 
Table 2. Clinical practical guidelines published from different professional societies [33].

\begin{tabular}{|c|c|c|c|}
\hline Association & Year & Country & Recommendation \\
\hline $\begin{array}{l}\text { Osteoarthritis Research Society } \\
\text { International (OARSI) }\end{array}$ & 2014 & USA & $\begin{array}{l}\text { Uncertain - varying quality of evidence } \\
\text { and conflicting results }\end{array}$ \\
\hline $\begin{array}{l}\text { National Institute for Health } \\
\text { and Care Excellence (NICE) }\end{array}$ & 2014 & UK & $\begin{array}{l}\text { Do not recommend-uncertainty and } \\
\text { varying quality throughout the } \\
\text { evidence. Hyaluronic acid is deemed to } \\
\text { not be cost-effective }\end{array}$ \\
\hline $\begin{array}{l}\text { Veterans Affairs/Department of } \\
\text { Defense (VA/DoD) }\end{array}$ & 2014 & USA & $\begin{array}{l}\text { Uncertain-insufficient evidence } \\
\text { available; however, IA-HA may be } \\
\text { considered if other treatment } \\
\text { options are unsuccessful }\end{array}$ \\
\hline $\begin{array}{c}\text { American Academy of } \\
\text { Orthopedic Surgeons (AAOS) }\end{array}$ & 2013 & USA & $\begin{array}{l}\text { Do not recommend-based on a lack } \\
\text { of IA-HA efficacy, not potential harm. } \\
\text { High variability in the quality of } \\
\text { current evidence noted. }\end{array}$ \\
\hline $\begin{array}{l}\text { American College of } \\
\text { Rheumatology (ACR) }\end{array}$ & 2012 & USA & $\begin{array}{l}\text { No recommendation made regarding } \\
\text { the use of IA-HA for initial knee OA } \\
\text { management; however, IA-HA is } \\
\text { recommended for patients } \geq 75 \text { that } \\
\text { have not had a satisfactory clinical } \\
\text { response to acetaminophen }\end{array}$ \\
\hline $\begin{array}{c}\text { American Academy of Family } \\
\text { Physicians (AAFP) }\end{array}$ & 2012 & USA & $\begin{array}{l}\text { Recommended as a consideration for } \\
\text { severe knee OA cases when other } \\
\text { treatment options have been } \\
\text { unsuccessful }\end{array}$ \\
\hline $\begin{array}{l}\text { Royal Australian College of } \\
\text { General Practitioners (RACGP) }\end{array}$ & 2009 & Australia & $\begin{array}{l}\text { Grade } \mathrm{C} \text { recommendation - there is } \\
\text { some evidence to suggest that IA-HA is } \\
\text { of some benefit for OA of the knee }\end{array}$ \\
\hline $\begin{array}{l}\text { National Collaborating Centre } \\
\text { for Chronic Conditions } \\
\text { (NCC-CC) }\end{array}$ & 2008 & UK & $\begin{array}{l}\text { Do not recommend-Highly variable } \\
\text { evidence regarding IA-HA efficacy, } \\
\text { deemed not cost-effective }\end{array}$ \\
\hline $\begin{array}{l}\text { Agency for Healthcare Research } \\
\text { and Quality (AHRQ) }\end{array}$ & 2008 & USA & $\begin{array}{l}\text { Uncertain-due to variability in trial } \\
\text { quality and unclear significance }\end{array}$ \\
\hline $\begin{array}{l}\text { European League Against } \\
\text { Rheumatism (EULAR) }\end{array}$ & 2003 & France & $\begin{array}{c}\text { No recommendation made regarding } \\
\text { the use of IA-HA for initial knee OA } \\
\text { management; however, an } \\
\text { acknowledgement of potential efficacy }\end{array}$ \\
\hline
\end{tabular}

USA-United States of America, UK-United Kingdom.

If there is swelling in the knee joint due to effusion, it is aspirated first. If no marked effusion present, enter the skin approximately $1 \mathrm{~cm}$ above the tibial plateau, and directed $15^{\circ}-45^{\circ}$ from the anterior knee surface vertical midline toward the intra-articular joint space [20] [24]. If the periosteum is met with the needle tip, redirect. Aspirate to rule out vessel puncture. Now we are ready to push the content. While pushing the content if there is flow obstruction, redirect (adjust) the needle tip again. Push the whole content, withdraw the needle and apply band-aid.

In case of knee effusion, aspiration is to be done first. After aspiration, the 
same syringe needle can be used for injecting hyaluronic acid into the joint. After the injection, according to the American College of Rheumatology survey, $71 \%$ of rheumatologists ask patients to decrease weight-bearing, often for 48 hours post injection.

The injection procedure bears the risks of adverse events so obtaining comparable safety is a reasonable choice which can be done by reducing the injection numbers. There are published literatures which reported on the safety using a single dose of hyaluronic acid [26] [27].

\section{Adverse Events of Intra-Articular Hyaluronic Acid}

The most common adverse events encountered are:

1) Arthralgia [26] [28] [29] [30]

2) Joint swelling [10] [24] [26] [28]

3) Bleeding at the injection site [26] [29]

4) Pain at injection site [10] [24] [29]

5) Reddening of injection site [24] [26] [30]

6) Allergic reaction [29]

7) Pseudoseptic [24]

8) Injection site pruritus [26]

These symptoms do not last long, resolves within a few days. Ice packs can help ease these symptoms. Nearly all published papers mentioned HA as a natural material which is a constituent of synovial fluid and cartilage matrix in normal knee joints and is safe to use [31] [32]. But eventually, the modification process for HA (manufacturing process) makes it as a foreign body to a certain limit, and that is why the adverse events mainly occur, which after the body system recognizes the molecule, it disappears automatically. To minimize the adverse events several studies have been done regarding hyaluronic acid of different molecular weight, cross-linkage and source (animal or bacterial).

\section{Risk Factors for Knee OA}

1) Common Risk Factors for Knee Osteoarthritis

2) Older age

3) Female

4) Inflammatory joint disease (e.g., infection, gout, rheumatoid arthritis)

5) Obesity (strongest modifiable risk factor)

6) Occupation requiring the repetitive knee bending

7) Previous knee injury (e.g., torn meniscus, intra-articular mechanical damage)

8) Genetic predisposition

9) Decreased bone mineral density

10) Muscle weakness

\section{Discussion}

There are multiple studies that support the use of HA injection, stating the relief 
of painful symptoms of the knee OA for a longer duration of action without any significant or severe adverse effects. Also, there are clinical practical guidelines published which do support, do not support or uncertain the use of intra-articular HA injection (Table 2).

The Amelia [29] study results showed that intra-articular injections of HA improved knee OA symptoms for up to 1 year. Yan et al. [10] showed that intra-articular injection of 6-mL hylan G-F 20 was effective in providing statistically significant pain relief and functional improvement up to 1 year in Chinese patients with primary knee OA. Out of 110 knees of 95 patients, 18 (16.4\%) knees experienced adverse events, including pain (14 knees), swelling (2 knees), and warmth ( 2 knees). All of the adverse events were mild and self-limiting. No patients required hospital admission or extra clinic visits for these self-reported events. Bannuru et al. [11] assessed the therapeutic trajectory of HA versus placebo. The conclusion was that HA is efficacious by 4 weeks, reaches its maximal effectiveness at 8 weeks and lasts up to 24 weeks. Święchowicz S. et al. [30], demonstrated that viscosupplementation using a hyaluronic acid preparation significantly reduced pain in the knee and improved its functioning, regardless of the form of osteoarthritis (primary and secondary knee osteoarthritis). The most common adverse events, articular pain and edema, as well as reddening of the injection site were noted. The therapeutic cycle involving hyaluronic acid injections performed once a week for three consecutive weeks and then after a 12-week gap, occurred to be the most effective after 6 months of therapy. Chareancholvanich et al. [34] concluded that patients who underwent high tibial osteotomy, suffering from primary medial compartment knee OA, intra-articular hyaluronic acid injections may be beneficial for increasing total cartilage volume and preventing the loss of lateral tibiofemoral joint cartilage after HTO (high tibial osteotomy). The intra-articular injection used, Hyalgan ${ }^{\circ}(20 \mathrm{mg} / 2 \mathrm{ml})$ of optimal molecular weight $(500,000-730,000 \mathrm{Da})$. The patients received 2 cycles (at 6-month intervals) of 5 weekly intra-articular hyaluronic acid injections after HTO operation. The authors of Cochrane review 2006 [35], concluded that viscosupplementation is an effective treatment for knee OA with beneficial effects on pain, function and global assessment, especially at the 5 to 13 week post-injection periods. In a randomized, double-blind, multicenter, placebo-controlled study, Huang et al. [36] showed that five weekly IA-HA administration of sodium hyaluronate (Hyalgan', $500-730 \mathrm{kDa}$ ) is safe, well tolerated, can improve joint functions and can provide sustained relief of pain in Asian patients with knee OA. Regarding the safety, adverse effects noted was mild or moderate. None of the noted adverse effects were considered to be related to study treatment. Altman et al. [37] stated that repeated injections of HA are effective, safe and well tolerated.

Maheu et al. [38] found F60027 (medium molecular weight hyaluronan product-F60027, Structovial) and Hylan G-F20 (Synvisc) equally effective in relieving pain in patients with knee degenerative OA. Berenbaum et al. [31] concluded 
that the intermediate MW HA preparation GO-ON (MW $800-1500 \mathrm{kD}, 25$ $\mathrm{mg} / 2.5 \mathrm{ml}$ ) is effective for knee osteoarthritis symptoms over 6 months after a 3-weekly injection course, and may be more effective than the reference low MW Hyalgan (MW $500-730 \mathrm{kD}, 20 \mathrm{mg} / 2 \mathrm{ml}$ ) formulation, with similar safety.

Ha et al. [26] reported that both IAHA preparations used in his study were non-animal (bacterial) origin, which might have contributed to the favorable safety profile due to low risk of developing immunological response. In Another study, M. Kirchner and D. Marshall [39] reported that 33.8\% of Bio-HA (high molecular weight hyaluronan produced by biological fermentation) patients and $40.4 \%$ of CL-HA (avian-derived hyaluronan that uses cross-linking to achieve high molecular weight) patients experienced adverse events. The most commonly reported events were arthralgia, back pain and joint effusion. The incidence of joint effusion was significantly higher in the CL-HA group. The significantly higher incidence of post-injection effusion in the CL-HA group provides a safety advantage for Bio-HA. Altman et al. [40] meta-analysis demonstrates that biological fermentation-derived HA had a significantly smaller incidence of effusion than did avian-derived HA. Biological fermentation-derived HA also demonstrated fewer acute flare-ups at the injection site than did avian-derived HA products, while high-molecular-weight products demonstrated the high rate of injection site flare-up. Author concluded that IA-HA products with a molecular weight $\geq 3000 \mathrm{kDa}$ and those derived from biological fermentation relate to superior efficacy and safety. The LBSA0103 is produced using BDDE (1, 4-butanediol diglycidyl ether) as the cross-linking agent. The safety risk associated with chemical states of BDDE present after cross-linking reaction is very low and the safety and metabolism of BDDE cross-linked HA have been well established [41]. Ha et al. [26] conducted his study to assess the efficacy and safety of a cross-linked hyaluronate (XLHA, single injection form, bacterial origin) compared with a linear high molecular hyaluronate (HMWHA, thrice injection form, bacterial origin) in patients with symptomatic knee osteoarthritis. Author concluded that a single injection of XLHA was non-inferior to three weekly injections of HMWHA in terms of WBP (weight bearing pain) reduction, and supports XLHA as an effective and safe treatment for knee osteoarthritis. R. Leighton et al. [27] conducted the study to compare NASHA (non-animal stabilized hyaluronic acid, bacterial synthesis, cross-linked) hyaluronic acid gel as single-injection intra-articular treatment for knee osteoarthritis against methylprednisolone acetate (MPA). This study shows that single injection NASHA (the author used Durolane $60 \mathrm{mg} / 3 \mathrm{ml}$ ) was well tolerated and non-inferior to MPA at 12 weeks. The benefit of NASHA was maintained for 26 weeks while that of MPA declined. An injection of NASHA at 26 weeks conferred long-term improvements without increased sensitivity or risk of complications. Increase in the molecular weight, stability, and viscosity of hyaluronic acid by cross-linking has been known to result in an extended duration of action with less number of intra-articular injections [31] [42] [43]. 
Vincent et al. [44] concluded that after intra-articular HA injection, reduction of knee pain might be due to improvements in synovial fluid viscosity and inflammation. Cartilage preservation may be dependent on how cytokine, oxidative stress profiles and viscosity change over time. EULAR Annual Congress, a team of French researchers, led by Florent Eymard at Henri Mondor University Hospital, found that HA shots were least likely to work for patients who were overweight or obese, had more severe arthritis (with more joint space narrowing), were older than 65 years, and/or had HA or corticosteroid shots (another type of joint injection) in the past.

\section{Conclusion}

Osteoarthritis is a chronic progressive disease of unknown aetiology causing destruction of cartilage and underlying bone. The most common and disgusting symptom is pain. Although there is no cure for osteoarthritis, many treatment options are available to help manage pain and keep people staying active. By bringing the single dose of hyaluronic acid in practice, most commonly occurring adverse events (pain, swelling, bleeding at injection site, erythema at injection site and pruritus) can be reduced. But regarding its safety and efficacy, more comparative study must be done between different molecular weight, cross-linkage and source (animal or bacterial). The use of intra-articular HA is thought to be safe except for mid-moderate adverse effects which resolve within a few days but regarding its treatment recommendation is controversial. The recommendation regarding the IA-HA treatment is controversial due to inconsistency within the clinical guidelines and the published literatures. Although it is reported to the relief of OA symptoms with viscosupplementation, it has never been shown to reverse the arthritic process. There are no medicines that can reverse or halt the progression of the disease. This pharmaceutical gap must be addressed in order to reduce the burden of $\mathrm{OA}$.

\section{References}

[1] Vinatier, C., Merceron, C. and Guicheux, J. (2016) Osteoarthritis: From Pathogenic Mechanisms and Recent Clinical Developments to Novel Prospective Therapeutic Options. Drug Discovery Today, 21, 1932-1937. https://doi.org/10.1016/j.drudis.2016.08.011

[2] McAlindon, T.E., et al. (2014) OARSI Guidelines for the Non-Surgical Management of Knee Osteoarthritis. Osteoarthritis and Cartilage, 22, 363-388. https://doi.org/10.1016/j.joca.2014.01.003

[3] Kelly, M.A., et al. (2003) Osteoarthritis and Beyond: A Consensus on the Past, Present, and Future of Hyaluronans in Orthopedics. Orthopedics, 26, 1064-1079.

[4] Neustadt, D.H. (2006) Intra-Articular Injections for Osteoarthritis of the Knee. Cleveland Clinic Journal of Medicine, 73, 897. https://doi.org/10.3949/ccjm.73.10.897

[5] Thomas, T., Amouroux, F. and Vincent, P. (2017) Intra Articular Hyaluronic Acid in the Management of Knee Osteoarthritis: Pharmaco-Economic Study from the Perspective of the National Health Insurance System. PLoS One, 12, e0173683. 
https://doi.org/10.1371/journal.pone.0173683

[6] Ishijima, M., et al. (2014) Intra-Articular Hyaluronic Acid Injection versus Oral Non-Steroidal Anti-Inflammatory Drug for the Treatment of Knee Osteoarthritis: A Multi-Center, Randomized, Open-Label, Non-Inferiority Trial. Arthritis Research \& Therapy, 16, R18. https://doi.org/10.1186/ar4446

[7] Bannuru, R.R., et al. (2014) Relative Efficacy of Hyaluronic Acid in Comparison with NSAIDs for Knee Osteoarthritis: A Systematic Review and Meta-Analysis. Seminars in Arthritis and Rheumatism, 43, 593-599. https://doi.org/10.1016/j.semarthrit.2013.10.002

[8] Fam, H., Bryant, J. and Kontopoulou, M. (2007) Rheological Properties of Synovial Fluids. Biorheology, 44, 59-74.

[9] Jordan, K., et al. (2003) EULAR Recommendations 2003: An Evidence Based Approach to the Management of Knee Osteoarthritis: Report of a Task Force of the Standing Committee for International Clinical Studies Including Therapeutic Trials (ESCISIT). Annals of the Rheumatic Diseases, 62, 1145-1155. https://doi.org/10.1136/ard.2003.011742

[10] Yan, C., et al. (2015) Efficacy and Safety of Hylan GF 20 Injection in Treatment of Knee Osteoarthritis in Chinese Patients: Results of a Prospective, Multicentre, Longitudinal Study. Hong Kong Medical Journal, 21, 327-332.

[11] Bannuru, R., et al. (2011) Therapeutic Trajectory Following Intra-Articular Hyaluronic acid Injection in Knee Osteoarthritis-Meta-Analysis. Osteoarthritis and cartilage, 19, 611-619. https://doi.org/10.1016/j.joca.2010.09.014

[12] Goldring, M.B. and Berenbaum, F. (2004) The Regulation of Chondrocyte Function by Proinflammatory Mediators. Clinical Orthopaedics and Related Research, 427, S37-S46. https://doi.org/10.1097/01.blo.0000144484.69656.e4

[13] Im, H.J., et al. (2008) Basic Fibroblast Growth Factor Accelerates Matrix Degradation via a Neuro-Endocrine Pathway in Human Adult Articular Chondrocytes. Journal of Cellular Physiology, 215, 452-463. https://doi.org/10.1002/jcp.21317

[14] Loeser, R.F. (2008) Molecular Mechanisms of Cartilage Destruction in Osteoarthritis. Journal of Musculoskeletal and Neuronal Interactions, 8, 303-306.

[15] Sundman, E.A., Cole, B.J. and Fortier, L.A. (2011) Growth Factor and Catabolic Cytokine Concentrations Are Influenced by the Cellular Composition of Platelet-Rich Plasma. The American Journal of Sports Medicine, 39, 2135-2140. https://doi.org/10.1177/0363546511417792

[16] Lee, A.S., et al. (2013) A Current Review of Molecular Mechanisms Regarding Osteoarthritis and Pain. Gene, 527, 440-447. https://doi.org/10.1016/j.gene.2013.05.069

[17] Wen, D.Y. (2000) Intra-Articular Hyaluronic Acid Injections for Knee Osteoarthritis. American Family Physician, 62, 565-567.

[18] Migliore, A. and Procopio, S. (2015) Effectiveness and Utility of Hyaluronic Acid in Osteoarthritis. Clinical Cases in Mineral and Bone Metabolism, 12, 31-33. https://doi.org/10.11138/ccmbm/2015.12.1.031

[19] Altman, R., et al. (2015) Hyaluronic Acid Injections Are Associated with Delay of Total Knee Replacement Surgery in Patients with Knee Osteoarthritis: Evidence from a Large US Health Claims Database. PLOS ONE, 10, e0145776. https://doi.org/10.1371/journal.pone.0145776

[20] Lockman, L.E. (2006) Knee Joint Injections and Aspirations: The Triangle Technique. Canadian Family Physician, 52, 1403-1404. 
[21] Murphy, D. and Soares, J.I. (2015) Knee Injections. Guide to Musculoskeletal Injections with Ultrasound. 95.

[22] Douglas, R.J. (2014) Aspiration and Injection of the Knee Joint: Approach Portal. Knee Surgery \& Related Research, 26, 1-6. https://doi.org/10.5792/ksrr.2014.26.1.1

[23] Chen, B., et al. (2014) Optimal Needle Placement for Ultrasound-Guided Knee Joint Injections or Aspirations. Journal of Trauma and Treatment, 3, 2167-1222.

[24] Hunter, D.J. (2015) Viscosupplementation for Osteoarthritis of the Knee. New England Journal of Medicine, 372, 1040-1047. https://doi.org/10.1056/NEJMct1215534

[25] Rice, D.A., et al. (2015) The Effects of Joint Aspiration and Intra-Articular Corticosteroid Injection on Flexion Reflex Excitability, Quadriceps Strength and Pain in Individuals with Knee Synovitis: A Prospective Observational Study. Arthritis Research \& Therapy, 17, 191-199. https://doi.org/10.1186/s13075-015-0711-5

[26] Ha, C.-W., et al. (2017) Efficacy and Safety of Single Injection of Cross-Linked Sodium Hyaluronate vs. Three Injections of High Molecular Weight Sodium Hyaluronate for Osteoarthritis of the Knee: A Double-Blind, Randomized, Multi-Center, Non-Inferiority Study. BMC Musculoskeletal Disorders, 18, 223-232. https://doi.org/10.1186/s12891-017-1591-4

[27] Leighton, R., et al. (2014) NASHA Hyaluronic Acid vs. Methylprednisolone for Knee Osteoarthritis: A Prospective, Multi-Centre, Randomized, Non-Inferiority Trial. Osteoarthritis and Cartilage, 22, 17-25. https://doi.org/10.1016/j.joca.2013.10.009

[28] Zhang, H., et al. (2015) Comparison of Two Hyaluronic Acid Formulations for Safety and Efficacy (CHASE) Study in Knee Osteoarthritis: A Multicenter, Randomized, Double-Blind, 26-Week Non-Inferiority Trial Comparing Durolane to Artz. Arthritis Research \& Therapy, 17, 51-60. https://doi.org/10.1186/s13075-015-0557-x

[29] Navarro-Sarabia, F., et al. (2011) A 40-Month Multicentre, Randomised Placebo-Controlled Study to Assess the Efficacy and Carry-Over Effect of Repeated Intra-Articular Injections of Hyaluronic Acid in Knee Osteoarthritis: The AMELIA Project. Annals of the Rheumatic Diseases, 70, 1957-1962. https://doi.org/10.1136/ard.2011.152017

[30] Swięchowicz, S., et al. (2012) Evaluation of Hyaluronic Acid Intra-Articular Injections in the Treatment of Primary and Secondary Osteoarthritis of the Knee. Polish Orthopedics and Traumatology, 22, 105-109.

[31] Berenbaum, F., et al. (2012) A Randomised, Double-Blind, Controlled Trial Comparing Two Intra-Articular Hyaluronic Acid Preparations Differing by Their Molecular Weight in Symptomatic Knee Osteoarthritis. Annals of the Rheumatic Diseases, 71, 1454-1460. https://doi.org/10.1136/annrheumdis-2011-200972

[32] Miller, L.E. and Block, J.E. (2013) US-Approved Intra-Articular Hyaluronic Acid Injections Are Safe and Effective in Patients with Knee Osteoarthritis: Systematic Review and Meta-Analysis of Randomized, Saline-Controlled Trials. Clinical Medicine Insights: Arthritis and Musculoskeletal Disorders, 6, 57-63.

[33] Altman, R.D., Schemitsch, E. and Bedi, A. (2015) Assessment of Clinical Practice Guideline Methodology for the Treatment of Knee Osteoarthritis with Intra-Articular Hyaluronic Acid. Seminars in Arthritis and Rheumatism, 45, 132-139. https://doi.org/10.1016/j.semarthrit.2015.04.013

[34] Chareancholvanich, K., Pornrattanamaneewong, C. and Narkbunnam, R. (2014) Increased Cartilage Volume after Injection of Hyaluronic Acid in Osteoarthritis Knee Patients Who Underwent High Tibial Osteotomy. Knee Surgery, Sports 
Traumatology, Arthroscopy, 22, 1415-1423. https://doi.org/10.1007/s00167-013-2735-1

[35] Bellamy, N., et al. (2005) Viscosupplementation for the Treatment of Osteoarthritis of the Knee. Cochrane Database of Systematic Reviews, 1, 1-59. https://doi.org/10.1002/14651858.CD005321

[36] Huang, T.-L., et al. (2011) Intra-Articular Injections of Sodium Hyaluronate (Hyalgan) in Osteoarthritis of the Knee. A Randomized, Controlled, Double-Blind, Multicenter Trial in the Asian Population. BMC Musculoskeletal Disorders, 12, 221-228. https://doi.org/10.1186/1471-2474-12-221

[37] Altman, R., et al. (2011) Safety and Efficacy of Retreatment with a Bioengineered Hyaluronate for Painful Osteoarthritis of the Knee: Results of the Open-Label Extension Study of the FLEXX Trial. Osteoarthritis and Cartilage, 19, 1169-1175. https://doi.org/10.1016/j.joca.2011.07.001

[38] Maheu, E., et al. (2011) Comparative Efficacy and Safety of Two Different Molecular Weight (MW) Hyaluronans F60027 and Hylan G-F20 in Symptomatic Osteoarthritis of the Knee (KOA). Results of a Non-Inferiority, Prospective, Randomised, Controlled Trial. Clinical and Experimental Rheumatology-Incl Supplements, 29, 527-535.

[39] Kirchner, M. and Marshall, D. (2006) A Double-Blind Randomized Controlled Trial Comparing Alternate Forms of High Molecular Weight Hyaluronan for the Treatment of Osteoarthritis of the Knee. Osteoarthritis and Cartilage, 14, 154-162. https://doi.org/10.1016/j.joca.2005.09.003

[40] Altman, R.D., et al. (2016) Product Differences in Intra-Articular Hyaluronic Acids for Osteoarthritis of the Knee. The American Journal of Sports Medicine, 44, 2158-2165. https://doi.org/10.1177/0363546515609599

[41] Schanté, C.E., et al. (2011) Chemical Modifications of Hyaluronic Acid for the Synthesis of Derivatives for a Broad Range of Biomedical Applications. Carbohydrate Polymers, 85, 469-489. https://doi.org/10.1016/j.carbpol.2011.03.019

[42] Chou, C.-W., et al. (2009) Hylan GF 20 Has Better Pain Relief and Cost-Effectiveness than Sodium Hyaluronate in Treating Early Osteoarthritic Knees in Taiwan. Journal of the Formosan Medical Association, 108, 663-672. https://doi.org/10.1016/S0929-6646(09)60387-9

[43] Strand, V., et al. (2012) A Multicenter, Randomized Controlled Trial Comparing a Single Intra-Articular Injection of Gel-200, a New Cross-Linked Formulation of Hyaluronic Acid, to Phosphate Buffered Saline for Treatment of Osteoarthritis of the Knee. Osteoarthritis and Cartilage, 20, 350-356. https://doi.org/10.1016/j.joca.2012.01.013

[44] Vincent, H.K., et al. (2013) Hyaluronic Acid (HA) Viscosupplementation on Synovial Fluid Inflammation in Knee Osteoarthritis: A Pilot Study. The Open Orthopaedics Journal, 7, 378-384. https://doi.org/10.2174/1874325001307010378 